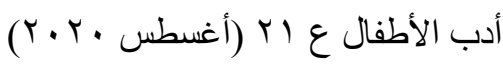
أحدث الرسائل العلمية

\title{
أحدث الرسائل العلمية في مجال الطقولة
}

عرض أ. هناء عبد العاطي عباس

كبير باحثين بمركز توثيق ويحوث أدب الطقل

رسائل الماجستير:

عنوان الرسالة: فاعلية بعض أثنكال أدب الطفل في تحسين صورة الذات عند الأطفال ذوي الإعاقة الحركية.

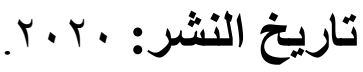

إثراف: أ.د. كمال الدين حسين محمد ـ أستاذ الأدب المسرحي و الدراسات الثعبية ـ كلية التربية للطفولة المبكرة، وأ.د. إبر اهيم زكي الصاوي ـ أستاذ التربية الحركية، و القائم بأعمال

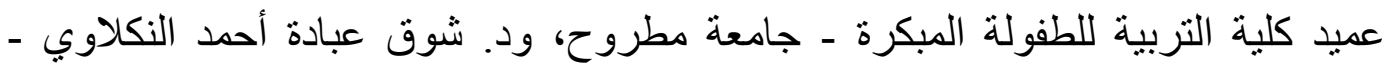
مدرس أدب الطفل ـ قسم العلوم الأساسية - جامعة مطروح. اسم الباحثّة: ميار أحمد عبد الجو اد محمد. الارجة العلمية: بحث للحصول على درجة الماجستير. الجامعة: جامعة مطروح. - البه الكلية أو المعهد: كلية التربية للطفولة المبكرة. القسم: قسم العلوم الأساسية.

أهمية البحث، ومستخلص له: سعت الدراسة لمعرفة أثر استخدام بعض أشكال أدب الطفل في تحسين صورة الذات لاى الأطفال ذوي الإعاقة الحركية، و الكثف عن مدى فعالية البرنامج القائم على بعض أثكال أدب الطفل في تحسين صورة الذات لدى الأطفال ذوي

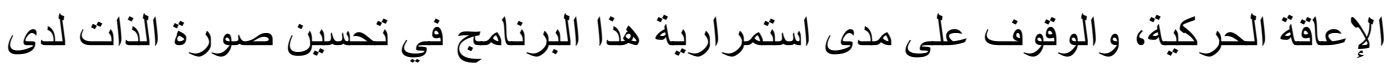
الأطفال ذوي الإعاقة الحركية بعد توقف البرنامج بثلاثة أشهر .

طبقت الباحثة در استها على عينة من الأطفال من ذوي الإعاقة الحركية، المنرددين على جمعية "من حقنا" لرعاية ذوي الإعاقة بمحافظة مطروح، خلال الفصل الدراسي الثاني

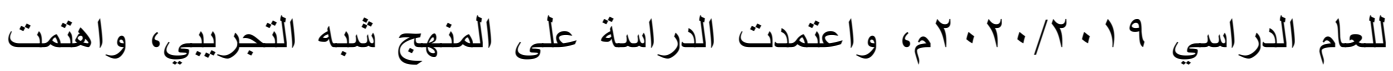
الباحثة بدراسة التغيير الحادث في صورة الذات عند الأطفال ذوي الإعاقة الحركية، من 


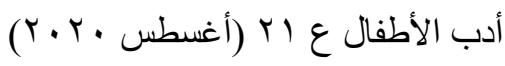
أحدث الرسائل العلمية

خلال بعض أثكال أدب الطفل (قصص الأطفال، وأغاني الأطفال، والنشاط التمثيلي)، ويحسب الفرق بين التطبيقات الثلاثة.

أهم التتائج: توصلت الدراسة إلى وجود فروق ذات دلالة إحصائية بين متوسطي رُتب درجات الأطفال ذوي الإعاقة الحركية في القياسين: القبلي، و البعدي، على المقياس المصور لصورة الذات للأطفال ذوي الإعاقة الحركية، لصالح القياس البعدي. وأوصت الدر اسة بإجر اء المزيد من الدراسات المتصلة بأدب الطفل لتنمية مختلف الجوانب الجسمية والاجتماعية والنفسية عند الأطفال ذوي الإعاقة الحركية، وإجراء دراسة طولية تتبع أثر البرنامج في تحسين صورة الذات عند الأطفال ذوي الإعاقة الحركية على المدى البعيد، ودراسة أثر البرامج القائمة على الأشكال المختلفة لأدب الطفل في تحسين صورة الذات عند الأطفال الأسوياء، وعند الأطفال ذوي الإعاقات الأخرى، كما أوصت الته بالتوسع في استخدام الأنشطة القائمة على أدب الطفل بأثكاله المختلفة مع الأطفال بشكل عام، ومع الأطفال ذوي الإعاقات بصورة خاصة. 


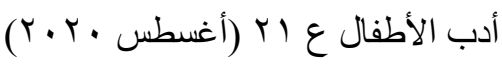
أحدث الرسائل العلمية

عنوان الرسالة: أثر استخدام المدخل الجمالي في تدريس العلوم على التحصيل المعرفي وتنمية التفكير البصري لاى تلاميذ الصف الرابع الابتدائي.

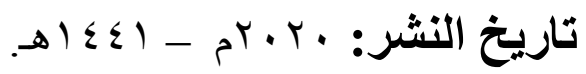
إثراف: أ.د. حنان مصطفى أحمد ذكي ـ أستاذ المناهج وطرق تدريس العلوم - كلية

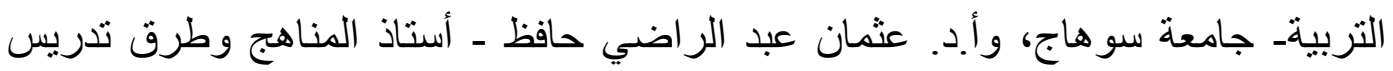
العلوم المتفر غلية التربية - جامعة سو هاج. اسم الباحثة: : صفاء محمد محمود بكر هيكل ـ معلمة علوم بمعهز حسام الدين الابندائي بإدارة جهينة الأزهرية. الارجة العلمية: بحث للحصول على درجة الماجستير.

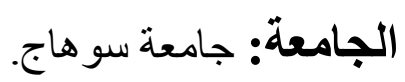
الكلية أو المعهد: كلية النربية. القسم: قسم المناهج وطرق التدريس. أهمية البحث ومستخلص له له تحدات مشكلة البحث فيما يلي: - ضعف مستوى التحصيل المعرفي في مادة العلوم للصف الر ابع الابتدائي. - - انخفاض مستوى التفكير البصري لاى تلاميذ الصف الرابع الابتدائي.

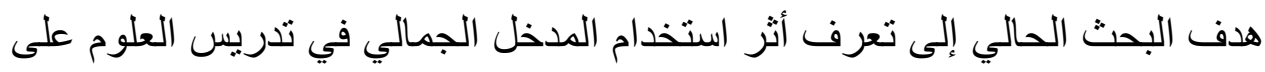
التحصيل المعرفي وتتمية مهارات التفكير البصري لاى تلاميذ الصف الرابع الابتدائي، ولتحقيق هذا الهذف تم اختبار مجموعتي البحث، وتم استخدام المنهج شبه التجريبي القائم على تصميم المعالجات التجريبية القبلية والبعدية من خلال مجمو عتين: إحداهما تجريبية، درس أفرادها الوحدة وفقًا للمدخل الجمالي، و الأخرى ضابطة، درس أفرادها نفس الوحدة فئه المختارة وفقًا لطريقة التنريس. نتائج البحث: - n

- وجود فرق دال إحصائيًا عند مستوى (0., •) بين مستوى درجات تلاميذ

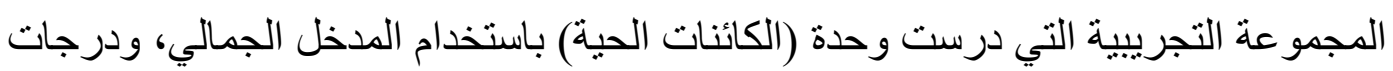




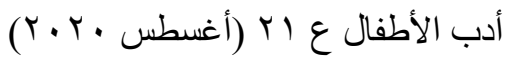
أحدث الرسائل العلمية

تلاميذ المجموعة الضابطة التي درست نفس الوحدة بالطريقة المعتادة في التطبيق البعدي لاختيار التفكير البصري في مادة العلوم، لصالح المجموعة التجريبية. - وجود فرق دال إحصائيًا عند مستوى (0., •) بين متوسطي درجات تلاميذ المجمو عة التجريبية التي درست وحدة (الكائنات الحية) باستخدام المدخل الجمالي، ودرجات تلاميذ المجموعة الضابطة التي درست نفس الوحدة بالطريقة المعتادة في التطبيق البعدي لاختبار التفكير البصري في مادة العلوم، لصالح المجموعة التجريبية. وجود أثر لاستخدام المدخل الجمالي في تدريس وحدة الكائنات الحية في تنمية التفكير البصري لتلاميذ الصف الر ابع الابتدائي.

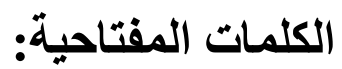

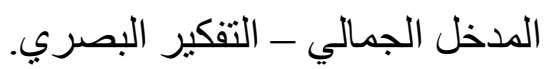




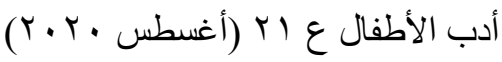
أحدث الرسائل العلمية

عنوان الرسالةة: غياب الأب، و علاقته بكل من الصلابة النفسية و المساندة الاجتماعية لاى عينة من تلاميذ الحلقة الثانية من التعليم الأساسي "در اسة سيكومترية ـ- إكلينيكية".

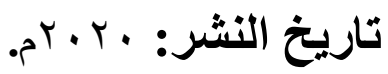

إشراف: أ.د يوسف عبد الصبور عبد الله صالح ـ أستاذ الصحة النفسية بكلية التربية ـ جامعة سوهاج، ود. وائل أحمد سليمان الثاذلي ـ مدرس الصحة النفسية بكلية التربية ـ جامعة سو هاج. اسم الباحث: أمين محمد أمين إبر اهيم - معلم كيمياء بإدارة جرجا التعليمية. الارجة العلمية: بحث للحصول على درجة الماجستير. الجامعة: جامعة سو هاج. الكلية أو المعهد: كلية التربية. القسم: الصحة النفسية. أهمبة البحث ومستخلص له

هدفت الدراسة إلى التعرف على علاقة غياب الأب بمستوى الصلابة النفسية و المساندة الاجتماعية لدى الأبناء بالحلقة الثانية من التعليم الأساسي، وتكونت عينة الدراسة

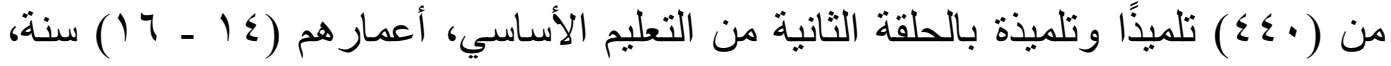
وتمثلت أدوات الدراسة في مقياس الصلابة النفسية (إعداد الباحث)، ومقياس المساندة الاجتماعية (إعداد: أسماء السرسي، و أماني عبد المقصود ؟ ا ـ ب) واختبارتفهم ( TAT ) التتائج: وجود علاقة ارتباطية دالة بين الصلابة النفسية والمساندة الاجتماعية، ووجود فروق دالة في متغيري: الصلابة النفسية، والمساندة الاجتماعية تعزى لمتغير حالة الأب لصالح الأبناء فاقدي الأب، ووجود فروق دالة في الصلابة النفسية، والمساندة الاجتماعية تعزى لسبب غياب الأب لصالح غائبي الأب بالوفاة، وعدم وجود فروق تعزى لمتغير الجنس إلا في بعد الالتزام من الصلابة النفسية لصالح الإناث. وفيما يتعلق بنتائج الفرض الإكلينيكي فقد جاءت منسقة مع النتائج السيكومنرية المذكورة، وتم مناقنة النتائج في ضوء التراث السيكومتري والإكلينيكي السابق في هذا الموضوع، بالإضـافة للخبرات و الثو اهد اليومية. 


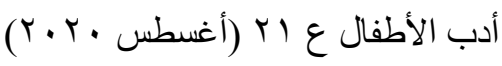
أحدث الرسائل العلمية

\section{رسالة دكتور اه}

عنوان الرسالة: المضامين التربوية في قصص الأطفال عند (عبد الحميد أبو سليمان): در اسة تحليلية.

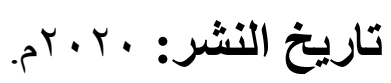
إشراف: أ.د. محمد إبراهيم عطوة ـ أستاذ أصول التربية المتقرغ بكلية التربية - جامعة المنصورة، وأ.د. علي عبد ربه حسين - أستاذ الإدارة التربوية بكلية التربية - جامعة المنصورة. اسم الباحثة: آلاء عبد الرحمن النقيب. الارجة العلمية: بحث للحصول على درجة الدكتور اه. الجامعة: جامعة المنصورة. الكلية أو المعهد: كلية التربية. القسم: أصول التربية.

أهمية البحث ومستخلص له: تحاول تلك الدراسة معرفة الدكتور (عبد الحمبد أبو سليمان)، وكيف استطاع تحويل هذا الفكر بأسلوب يناسب الطفل والمراهق من خلال قصصه التربوية الثلاثة: (جزيرة البنائين)، (كنوزجزيرة البنائين)، و(القرد الذكى لا يعرف الحساب)، وذللك من خلال الإجابة عن التساؤلات التالية: ما أهم المفاهيم والمبادئ و التوجهات التربوية التي اشتملت عليها كتابات د. (عبد الحميد أبو سليمان) في الجوانب السياسية والاقتصادية والاجتماعية؟، وكيف اشتملت قصص د. (عبد الحميد أبو سليمان) على تلك المفاهيم والمبادئ والتوجهات التربوية بأسلوب يتناسب مع إنقرائية الطفل؟ وللإجابة عن أسئلة الدراسة فقد جاعت فصولها على النحو التالي: الفصل الأول: الإطار العام للارراسة: يتضمن المقدمة، ومشكلة الدراسة، وأهداف الدراسة، و أهمية الدراسة، و ونهج الدراسة، ومصطلحات الدراسة، والدراسات السابقة العربية و الأجنبية. 


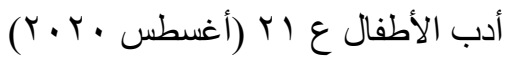
أحدث الرسائل العلمية

الفصل الثانى: (عبد الحميد أبو سليمان)، نشأته وتطوره الفكري، وعرض هذا الفصل كيف

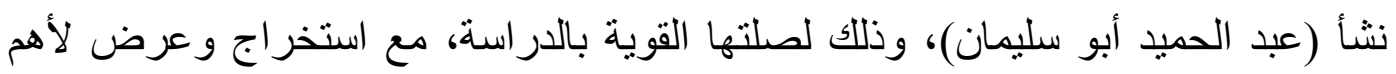
المضامين التربوية المتضمنة في تلك الكتب. الفصل الثالث: تحليل محتوى قصص الأطفال عند (عبد الحميد أبو سليمان): ويشتمل هذا

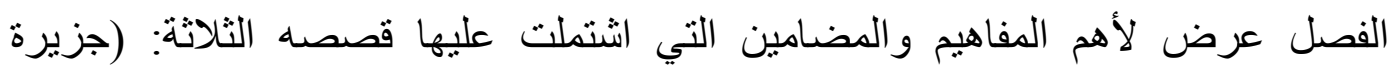
البنائين)، (كنوزجزيرة البنائين)، و أخيرًا (القرد الذكى لا يعرف الحساب).

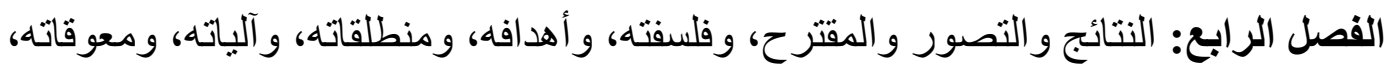

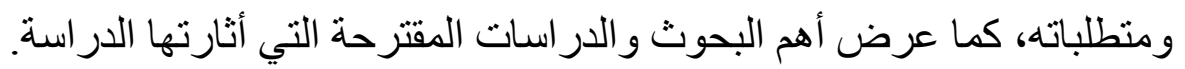

